\title{
Bandidos y Perros gañanes en la crónica chilena del Siglo XX
}

\author{
GLORIA FAVI CORTÉS
}

Este estudio propone una lectura Semiótico-Textual para integrar en un significado global los discursos visuales, historiográficos y literarios que dan cuenta de la construcción identitaria de la marginalidad rural en Chile en los inicios del siglo XX.

La Semiótica- considerada actualmente como una multidisciplina que interpreta todo tipo de signos que quedan impresos en una cultura- nos permitirá proyectar sobre la espectacularidad y velocidad del siglo XXI, las figuras virtuales de los bandidos, ociosos y vagabundos(clasificados en el mismo estatuto delictual) que permanecen retenidas en la escritura y en las fotografías amarillentas de las secciones policiales; de esta forma, el mundo virtual de los inicios del siglo XIX nos resultará contemporáneo y cotidiano y tal vez nos permitirá reconocer una cierta historia evolutiva de los conceptos morales; ciertos signos culturales que dejan huellas materiales observables frente a la aceleración del tiempo, las imágenes y la historia en nuestra actual sociedad cibernéticas que ha creado nuevas formas para establecer el Dominio el Poder y la Subordinación.

La ausencia de escritos directos que den cuenta, sin mediaciones, de la subjetividad de la marginalidad en los inicios del siglo XX, nos permitiría reconocer a través de las representaciones visuales, las canciones y el folklore, los signos de identidad de esa comunidad de culturas indescifrables para los nuevos estatutos de subjetividad que intenta imponer la actual sociedad global.

El discurso narrativo y visual representado en la revista Sucesos (Valparaíso) 24 de Agosto 1902, nos devuelve las huellas de una presencia que reaparece en forma obsesiva en la Historia de Chile y se filtra desde las fotografías de las secciones policiales, las revistas, las canciones, los diarios y el folklore, para dejar señales indelebles de una existencia que se niega a la estigmatización y al olvido De esta forma el relato de algunos hechos de violencia situados en un tiempo ajeno y el uso particular de un lenguaje que refleja y construye la particular identidad de los grupos anómalos, nos permitirá en el siglo XXI, reconstruir sobre la superficie del mismo lenguaje institucional que los nombra, las señales silenciosas del casi inexistente discurso oficial que se refiere a la marginalidad rural en el siglo XIX e inicios del siglo XX. 
Por esto, la voluntad de verdad y la crítica valorativa que se esconde tras el uso de la retórica en la crónica de la Revista Sucesos, estaría desplegando el vasto mundo de los vagabundos, vagamundos, mal entretenidos y perros gañanes que desde el siglo XVII realizaban sus recorridos de sobrevivencia por todas las zonas de Chile. Así sus huellas pueden seguirse hacia el Norte, en las zonas mineras; en las grandes ciudades del centro; o en las zonas rurales del Sur... "todos los días se ven en las plazas $y$ calles, jornaleros robustos ofreciendo sus servicios a cambio de especies...se ven amanecer en las puertas de las casas de campo mendigando ocupación ....Soy continuo espectador de esto mismo en las obras públicas de la capital, en que se presentan enjambres de infelices a solicitar trabajo, rogando que se les admita...." son las observaciones del síndico del Real Consulado en 1796.

En el siglo XVIII los testimonios dejan constancia del creciente número de estos individuos sueltos que solicitan trabajo o piden limosna en las plazas, pero esta percepción se modifica en el siglo XIX cuando el censo de 1865 enumera 120.000 gañanes sin destino fijo y las voces -con creciente alarma- hablan de "nubes de mendigos ", "lobos merodeadores", "abridores de forados " " comedores de fruta" El siglo XIX, en los inicios de la era republicana, no sólo registraba testimonios sobre las actividades ilícitas de los vagabundos, mendigos e indigentes; exterioriza también el temor a las acciones violentas de los ilegales que sobrepasan las labores correctivas del Cuerpo de Vigilantes y Serenos que creó el Ministro Portales el 20 de Junio de 1830 . En esta atmósfera de crisis y deficiencias de control social, nace en 1864 el cuerpo de "guardias comisionados"; es el inicio de la primera sección de pesquisas que tendrá como" objetivo descubrir los ladrones y malhechores " 3

El comisionado será la presencia manifiesta para el control del delito y la expedita administración de justicia frente al notorio aumento de la delincuencia causada por la crisis agrícola de 1857 que cerró los mercados del trigo de California y Australia y que en 1870 -frente a las magras condiciones laborales que ofrecía la hacienda- empujó a miles de hombres y mujeres a ocupar trenes y caminos para dirigirse a las zonas mineras y a las grandes ciudades.

Teun van Dijk (2000) señala que una teoría explícita que relacione Ideología y Lenguaje se encuentra en construcción, pero nos interesa -como propósito central en nuestra investigación - la semiótica y gramática social que propone la lingüísti-

1 M. De Salas. Representación al Ministro de Hacienda...en Miguel Cruchaga: Estudio sobre la Organización y Hacienda Pública de Chile (Santiago 1878). Apéndice II, Libro I, p.275

2 Salazar, G. Labradores, peones y proletarios. Formación y crisis de la sociedad popular chilena del siglo XIX (Santiago 1985)

3 Municipalidad de Valparaíso. Índice General del Archivo. Primera parte. Actas Municipales 1791 a 30 de junio de 1895. Valparaíso, 1896, p.496 
ca sistémica de Michael Halliday(1978) sobre algunas estructuras sintácticas de oraciones que pueden verse sesgadas por las perspectivas ideológicas del que usa el lenguaje. Esta preocupación por los problemas reales del mundo coincide con las orientaciones que ha formulado Teun A van Dijk (Ideologías 2000) para estudiar el discurso, el poder y la ideología desde una perspectiva multidisciplinaria que involucra la lingüística, la poética, la semiótica, la sociología ,la antropología, la historia y la investigación en comunicación.

Declarada mi adhesión a las orientaciones que propone el Análisis del Discurso, realizaré un análisis crítico sobre la ideología del discurso narrativo y visual que se propone en una de las páginas de la Revista Sucesos.(1902)

Pero mis intenciones no son informativas; pretendo que en este encuentro de tiempos diferentes, mi lectura sea la creación simbólica de un mundo que construye su sentido y contenidos ideacionales en forma independiente de la causalidad histórico- social. De esta forma, las supuestas verdades oficiales- fijadas en los márgenes definidos del texto- imprimirán sus propias consecuencias en cuanto se registran como documentos de la acción humana que señalan la temporalidad abierta de los signos culturales.

Las fotografías de los delincuentes rurales que ilustran el texto de la Revista Sucesos publicada en Valparaíso del 24 de Agosto de 1902 constituyen por sí mismas datos de un espacio vivo y dinámico que nos habla, por ausencia, de la soledad, violencia y fealdad en este mundo posible... "Abran sus ojos y verán cómo diariamente familias enteras abandonan sus casas y parten; ¿adónde?. Ni ellos lo saben. Su único propósito es dejar un lugar que no les da para vivir... recorran nuestros caminos y verán muchas familias trasladándose hacia la ciudad para aumentar la ya existente indigencia....." (3) escribe un chileno prominente en 1850. Datos no confirmados estiman que entre 1865 a 1907, 481.000 campesinos abandonaron las áreas rurales de Chile para avecindarse en las grandes ciudades. (Valparaíso, Santiago y Concepción) Este hacinamiento de la" gente suelta" provocó un notorio aumento de la delincuencia urbana y un efectivo control policial que situó a Chile entre los pioneros del continente en el uso de la fotografía forense. La Policía Secreta registraba el 14 de abril de 1874 una colección de 474 retratos de delincuentes. ${ }^{4}$

Fuera de los registros policiales, casi no existen fotografías que nos hablen de la sociabilidad de los ociosos y mal entretenidos; creo que jamás se ha reproducido la alegría que podría haber reflejado su inactividad productiva como un desafío manifiesto a la Sociedad de los Hacendados. Notamos además que generalmente las

4 Fotografías de la Revista Sucesos, Valparaíso, 4 de Agosto de 1902, página 16. Reproducción autorizado por el Archivo Fotográfico de la Biblioteca Nacional de Chile. 
fotografías- que muestran la sociabilidad del bajo pueblo - reproducen ejemplarmente su dura labor, éstos se encuentran en sus lugares de trabajo y cercados por palas, arados y otros instrumentos de trabajo.

Algunas fotografias de los inicios del siglo XX y que reproducen algunos textos ${ }^{5}$, señalan la trágica sociabilidad de los malhechores; Bandidos presos con sus armas acusados de salteadores de caminos (1900) y Los bandidos y sus captores (1925). Naturalmente, estos registros, jamás reflejarán la historia de su sociabilidad, porque basta la torva mirada de su solitario registro en los Archivos Policiales para reconstruir la ilegal cabalgata de sus rencores que les ha obligado a transitar por todos los caminos de Chile.

Las fotografías forenses a las cuales nos referiremos a) Mauricio Ponce Bastías, alias Cacho de Tinta b)Víctor Araya Plaza, alias El Natito c) Avelino del Carmen González Núñez, alias El Canario; reproducen una semántica visual complementaria y con metas definidas para intensificar la fealdad, maldad y bestialidad que marca las desigualdades de una clase social. Correspondería además a ciertas instancias críticas del Poder de la época para sancionar- no sólo en el nivel judicial -sino a través de un lenguaje satírico que ridiculiza sus imágenes a quienes se extralimitan y escapan de sus márgenes. De esta forma se nos entrega, la doble dimensión de un discurso visual potenciado por la subjetividad de un habla que califica y determina un modo de mirar "es una circunstancia curiosa la de que estos tres sujetos sean los que tienen peor catadura entre toda aquella desarrapada colección de horribles fisonomías."

De esta forma, las ropas viejas, arrugadas y sucias; los cabellos tonsurados de Cacho de Tinta y el Natito y sus miradas pasivas frente a la cámara construyen su propio espacio de desarraigo, pero a la vez establecen un interesante contrapunto con la actitud despectiva que estaría reflejando El Canario. Notamos que él no tiene sus ojos fijos en la cámara, sus cabellos y sus ropas lucen diferentes, se nos advierte que él es un futre, sabe leer y escribir; entonces con soslayada dignidad desvía la humillación que le propone el fichaje policial ¿Cómo lo ha logrado? ¿Es posible que la institucionalidad policial respete también a la aristocracia del crimen?

Creemos que algunas pistas- en la superficie del lenguaje institucional de la crónica -estarían revelando algunos signos de identidad que marcan la inestabilidad y desarraigo de los delincuentes y gañanes sin destino fijo "Cacho de Tinta natural de San Fernando fue tomado preso en Batuco fue enviado a Valparaiso para esclarecer sus delitos. El Natito natural de Carrizal Bajo enviado a Valparaiso a pagar sus fechorias. El Canario natural de Santiago ha estado preso en Santiago, Valparaiso y Viña del Mar". Su vagabundaje incierto se ve reflejado en la expresividad activa y movible de un

5 Daniel Barros Grez, Proyecto de división, p.4 
lenguaje que va imitando los trayectos de los ociosos y mal entretenidos y con cuyo poder innominado estaría ordenando y organizando sus transportes desde un espacio a otro.

Las estructuras sintácticas se ven sesgadas por las perspectivas ideológicas en el uso del lenguaje; así los verbos en voz activa señalan las acciones negativas de la marginalidad para enfatizar su violencia y descontrol" registra historias de crimenes " "pretendió robar un billete" "se ha hecho temible por su destreza para manejar el corvo " Discipulo aventajado del Capiro y del Cachurero."

La voz pasiva se utiliza para señalar el sometimiento y absoluto control institucional que neutraliza sus repudiables acciones.

"fue tomado preso.reconocido e identificado por la sección de pesquisas. ha sufrido antes de ahora otras condenas fue enviado a este puerto para el esclarecimiento de sus delitos"

El uso de los adjetivos constituye categorías de percepción, principios de visión y construcción de mundo que señalan cómo un grupo social dominante utiliza el lenguaje para subrayar su distancia social y moral" Sabe leer y escribir y es una especie de futre entre las gentes de su laya"

"El Natito tiene por nombre de pila Victor Araya Plaza, pero desde la ya lejana época en que adoptó su apodo, nadie lo llama de otra manera "

Podemos imaginar cómo Víctor Araya Plaza, ha construido su propia identidad y organizado su comportamiento en función a la información que extrae del mundo exterior; así, porque el mundo exterior es violento "se ha hecho temible por su destreza para manejar el corvo"; porque es salteador, vago, sin oficio conocido y de oscuro origen "tiene malas entrañas".

Su apodo "El Natito"-su propia autoconstrucción - la verdadera conciencia que tiene de sí mismo, es la identidad que nos permitirá reinvestigar el contexto real que atrapará algunos restos en las huellas que van dejando los grupos anómalos en los inicios del siglo XX.

Por esto, nos será necesario analizar cómo se inscribe el conocimiento cotidiano y la posición valorativa institucional que orienta las conductas de los delincuentes y que se estaría proyectando en esta crónica.

Así, la sociabilidad para los miles de vagabundos, salteadores y delincuentes que ocupaban los márgenes de las grandes ciudades, se encontraría restringida hacia las visitas frecuentes a las oficinas de pesquisas y cárceles, a la información que reciben del mundo exterior sobre su propia condición social y que estaría generando la violenta autoconstrucción de su identidad. Comprobamos que el funcionamiento social de su organismo se va adecuando a la percepción y al modelo físico de horror y rechazo que 
generan sus acciones "estos tres sujetos sean los que tienen peor catadura entre toda aquella desarrapada colección de horribles fisonomias "

Pero ¡ cómo se ha ejercido la resistencia social en el discurso de la contracultura? ¿dónde estaría registrada, sin mediaciones, su réplica?

Sabemos que su discurso no se encuentra registrado en la historia oficial-pero sus huellas las encontramos en la ficción literaria, las canciones populares, el folklore, la poesía popular y en el desenfado de sus declaraciones judiciales; así, Pascual Pérez, declara por oficio ser "jugador de bolos", Dionisio Faúndez afirma que su oficio es "andar andando" 6

El discurso valorativo del cronista en los inicios del siglo XX; narra, actúa, condena y perdona; así contribuye a construir los lugares comunes más efectivos que estarían reflejando estas maneras de vida improductiva.

De esta forma nos resulta irónico el contra-discurso épico que relata las grandes hazañas de Cacho de Tinta, "natural de San Fernando, salteador y monrero registrando en su historia de crimenes tres homicidios, nueve salteos y otros varios delitos pretendió robar un billete de diez pesos a un vendedor ambulante ". No es menos espectacular la vida de El Natito, se nos informa que" Entre los salteadores de la actual generación se ha becho temible por su destreza para manejar el corvo y sus malas entrañas. Discipulo aventajado del Capiro y del Cachuchero, es, sin embargo, un grande admirador de Cacho de Tinta, a quien respeta por su fuerza hercúlea. El Canario es un vago conocido que sabe leer y escribir y es un futre entre las gentes de su laya.

El cronista acude a numerosos efectos de superficie para construir el relato desde una perspectiva que simula el discurso de la contracultura; así, con una ironía trágica utiliza la retórica para destacar las variadas historias de crímenes, biografías criminales, historias de destrezas con armas prohibidas, discípulos aventajados del crimen, respeto a la fuerza criminal y fallidas acciones valerosas y por oposición-en un silencio tácito- nosotros empezamos a imaginar las vidas plenas de luz; las biografías de los grandes hombres, la historia de sus destrezas intelectuales, los discípulos aventajados en disciplinas del saber, los admiradores de las hazañas de Hércules y las efectivas acciones valerosas.

Pero el cronista reconoce una semejanza en estos mundos contrapuestos “ una ley moral que se cumple en todas las esferas, y que aún en el mundo del crimen, el bombre se encuentra con el hombre, tal como establece el vaticinio de los sagrados libros"; es la amistad, que permite el reencuentro en el calabozo entre Cacho de Tinta, el Natito y el Canario, tal vez el único espacio fijo que los reúne en su vida de nómades.

6 Hernández, Roberto. De la Policía Secreta a la Policía científica, (1994), p.25 
Finalmente; la lectura de estas viejas fotografías y el ingreso inopinado hacia los espacios estereotipados que construye el discurso de la crónica en los inicios del siglo XX nos permitiría reinscribir la historia social del pueblo de Chile en una nueva dimensión de la memoria-nuestra patria más interior - aquella que nos impide ser errantes en nuestro suelo nativo y que aún se resiste al adormecimiento, al olvido y al opaco empobrecimiento que imponen los nuevos modelos de coerción y dominio.

\section{Bibliografía}

Bauer, Arnold J.

1975 Chilean Rural Society From de Spanish Conquest to 1930, Cambridge Press (Trad. esp. Paulina Matta) Santiago: Andrés Bello (1994)

Contador, Ana María

1998 Los Pincheira, un caso de Bandidaje Social (Chile 1817-1832). Santiago: Bravo y Allende

Guevara, Tomás

1890 Historia de Curicó. Santiago : Editorial Andujar 1997

Hernández, Roberto

1994 De la Policía Secreta a la Policía Científica. Santiago : E. Policía de Investigaciones.

Salazar, Gabriel

1985 Labradores, peones y proletarios. Formación y crisis de la sociedad popular chilena del siglo XIX: E.Sur, Santiago. Chile.

Nota : Este artículo es parte de una investigación financiada por el D. I. D ( 2003 código Soc 0312-1) 